\title{
Capturing Proteins that Bind Polyunsaturated Fatty Acids: Demonstration Using Arachidonic Acid and Eicosanoids
}

\author{
Thomas G. Brock
}

Received: 25 August 2007/ Accepted: 6 November 2007/Published online: 15 December 2007

(C) AOCS 2007

\begin{abstract}
Polyunsaturated fatty acids (PUFA) and their biological derivatives, including the eicosanoids, have numerous roles in physiology and pathology. Although some eicosanoids are known to act through receptors, the molecular actions of many PUFA remain obscure. As the three-dimensional structure of eicosanoids allows them to specifically bind and activate their receptors, we hypothesized that the same structure would allow other proteins to associate with PUFA and eicosanoids. Here, we demonstrate that biotinylation of arachidonic acid and its oxygenated derivatives 5-hydroxyeicosatetraenoic acid (5HETE) and leukotriene (LT) $\mathrm{B}_{4}$ can be used to pull down associated proteins. Separation of proteins by two-dimensional gel electrophoresis indicated that a large number of proteins bound each lipid and that proteins could distinguish between two enantiomers of 5-HETE. Individual proteins, identified by matrix assisted laser desorption/ ionization-time of flight mass spectrometry, included proteins that are known to bind lipids, including albumin and phosphatidylethanolamine-binding protein, as well as several novel proteins. These include cytoskeletal proteins, such as actin, moesin, stathmin and coactosin-like protein, and $\mathrm{G}$ protein signaling proteins, such as Rho GDP dissociation inhibitor 1 and nucleoside diphosphate kinase B. This method, then, represents a relatively simple and straightforward way to screen for proteins that directly associate with, and are potentially modulated by, PUFA and their derivatives.
\end{abstract}

T. G. Brock $(\bowtie)$

Department of Internal Medicine, University of Michigan,

Ann Arbor, MI 48109, USA

e-mail: brocko@umich.edu
Keywords Leukotrienes .

5-Hydroxyeicosatetraenoic acid · Moesin - Stathmin ·

Coactosin-like protein - Rho GDP dissociation inhibitor 1 . Nucleoside diphosphate kinase B
Abbreviations
ARA Arachidonic acid
ACH Arachidic acid
HETE Hydroxyeicosatetraenoic acid
HpETE Hydroperoxyeicosatetraenoic acid
LT Leukotriene
MALDI- Matrix assisted laser desorption/ionization-
TOF time of flight
PUFA Polyunsaturated fatty acid
RBL Rat basophilic leukemia

\section{Introduction}

Polyunsaturated fatty acids (PUFA) play important roles in health and disease. For example, increasing the consumption of $\omega-3$ PUFA reduces the risk of coronary heart disease [1-3] and decreases ischemic heart disease [4, 5]. On the other hand, the $\omega$-6 PUFA arachidonic acid (ARA) can form $\omega-6$ eicosanoids that exacerbate arrhythmogenic events $[6,7]$ and decreasing excessive $\omega-6$ eicosanoid action can reduce the risk of ischemic heart disease [8-10]. Although these PUFA have profound effects on physiology, the specific actions of PUFA at the molecular and cellular levels are diverse and poorly understood.

Chemically, PUFA include long chain hydrocarbon molecules with numerous carbon-carbon double bonds. The double bonds represent sites of chemical reactivity 
with potential for enzymatic modification. For example, ARA is a twenty carbon PUFA with four double bonds (20:4). It can be modified by the enzyme 5-lipoxygenase, which inserts molecular oxygen at the fifth carbon to produce $5(S)$-hydroperoxyeicosatetraenoic acid $(5(S)$-HpETE; reviewed in [11]). This PUFA can be modified by peroxidases to produce $5(S)$-hydroxyeicosatetraenoic acid $(5(S)$ HETE), a biologically active monohydroxylated PUFA. Alternatively, 5(S)-HpETE can be further metabolized along the 5-lipoxygenase pathway to produce the dihydroxylated PUFA leukotriene (LT) $\mathrm{B}_{4}$ or the glutathionecontaining $\mathrm{LTC}_{4}$. Whereas ARA induces apoptosis in neurons [12] and in leukemic cells [13, 14] or activates a variety of cell types $[15,16], \mathrm{LTB}_{4}$ and 5(S)-HETE are best known as chemoattractants and activators of leukocytes, and $\mathrm{LTC}_{4}$ is recognized to promote contraction of smooth muscle and secretion of mucus from goblet cells (reviewed in [17]). Thus, enzymes recognize specific PUFA and alter them to produce a variety of novel constructs that have unique functions. The multitude of products that can be produced from ARA are called eicosanoids, whereas the smaller group produced solely by the 5-lipoxygenase pathway are the LT.

Structurally, the carbon-carbon double bonds in PUFA provide a degree of rigidity that is not found in saturated FA. As a result, each of the PUFA and their derivatives has a unique three-dimensional structure. This structure allows these lipids to interact with specific receptors. For example, $\mathrm{LTB}_{4}$ binds to and activates two G-protein coupled receptors, the high affinity $\mathrm{BLT}_{1}$ [18] and the lower affinity $\mathrm{BLT}_{2}$ [19]. Similarly, $\mathrm{LTC}_{4}$ activates two other receptors, $\mathrm{CysLT}_{1}$ and $\mathrm{CysLT}_{2}$. Consistent with the high specificity of lipid for protein, $\mathrm{LTB}_{4}$ does not activate $\mathrm{CysLT}_{1}$ or $\mathrm{CysLT}_{2}$ at physiological concentrations, and $\mathrm{LTC}_{4}$ does not activate $\mathrm{BLT}_{1}$ or $\mathrm{BLT}_{2}$. Relevant to this study, the interaction of these eicosanoids with their receptors results in conformational changes of the receptors with their consequential activation. This suggests that, if PUFA associate with non-receptor proteins, they may alter protein shape, resulting in modification of protein function.

We hypothesized that the distinctive structure of PUFA and eicosanoids should allow them to interact with specific soluble proteins other than traditional receptors. For example, it is known that ARA can bind directly to protein phosphatase 5 [20], binds to [21] and activates [22] S100A8/A9, and directly activates a GTP-binding protein in neutrophils [23]. Here, we describe a method for objectively capturing proteins that associate with PUFA and eicosanoids. We use proteins from the rat basophilic leukemia (RBL-1) cell line because it is mast cell like, in that it releases ARA, makes LT and responds to LT.

\section{Materials and Methods}

Cells and Cell Lysates

RBL cells (RBL-1, American Type Culture Collection, Manassas, VA) were grown under $5 \% \mathrm{CO}_{2}$ in Minimal Essential Medium alpha (Invitrogen) with $10 \%$ fetal bovine serum, 182 units $/ \mathrm{mL}$ penicillin $\mathrm{G}$ sodium, $182 \mu \mathrm{g} / \mathrm{mL}$ streptomycin sulfate, $455 \mu \mathrm{g} / \mathrm{mL}$ amphotericin B. $2 \times 10^{7}$ cells were suspended in lysis buffer $(137 \mathrm{mM} \mathrm{NaCl}$, $10 \mathrm{mM}$ phosphate buffer, $\mathrm{pH} 7.4,2.7 \mathrm{mM} \mathrm{KCl}, 1 \mathrm{mM}$ EGTA, protease inhibitor cocktail (Roche Applied Science, Indianapolis, IN), sonicated, centrifuged at $14,000 \times g$ $\left(5 \mathrm{~min}, 4{ }^{\circ} \mathrm{C}\right.$ ) and supernatant collected as total soluble proteins from RBL cells.

\section{Isolation of PUFA-Binding Proteins}

PUFA (ARA, ACH, 5(S)-HETE, 5(R)-HETE, or $\left.\mathrm{LTB}_{4}\right)$ were biotinylated using the EZ-Link Biotin PEO-Amine kit (Pierce, Rockford IL), according to manufacturer's directions. Briefly, PUFA were diluted to $10 \mathrm{mg} / \mathrm{mL}$ in 2( $N$-morpholino)ethane sulfonic acid (MES) buffer, $\mathrm{pH} 4.5$, mixed with biotin $(21 \mathrm{mg} / \mathrm{mL})$ and 1-ethyl-3-[3-dimethyl aminopropyl] carbodiimide hydrochloride crosslinker $(20 \mathrm{mg} / \mathrm{mL})$, with mixing on rotator for $2 \mathrm{~h}$ at RT. Total soluble proteins from RBL cells were mixed with FAbiotin solution, without purification of the FA-biotin preparation, at an approx 1:1 molar ratio, on rotator for $1 \mathrm{~h}$ at RT. Samples of the cell protein/FA-biotin preparation were mixed with avidin immobilized on beaded agarose (Pierce) for $1 \mathrm{~h}$ at RT and centrifuged $1 \mathrm{~min}$ at $3,000 \times g$. The resulting pellet was washed three times with TBS and FA-binding proteins recovered by elution with $400 \mathrm{mM} \mathrm{NaCl}$ in PBS. In some experiments, the supernatant, partially depleted of FA-binding proteins, was mixed with additional immobilized avidin and centrifuged to remove remaining FA-binding proteins, producing a protein fraction that was highly depleted of FA-binding proteins.

\section{Gel Electrophoresis and Protein Identification}

Protein samples were dialyzed overnight in PBS with stirring at $4{ }^{\circ} \mathrm{C}$, mixed with SDS-PAGE sample buffer, boiled, separated by SDS-PAGE using a $12 \%$ Tris- $\mathrm{HCl}$ gel and stained with Coomassie. For two-dimensional gel electrophoresis, samples were mixed with isoelectric focusing buffer and separated using ReadyStrip IPG strips, pH 3-10, in the Protean IEF Cell (Bio-Rad Laboratories, Hercules CA). After focusing, strips were equilibrated 
using iodoacetamide, separated by SDS-PAGE using a $12 \%$ Tris- $\mathrm{HCl}$ gel and stained with Coomassie. Isolated proteins were subjected to matrix assisted laser desorption/ ionization-time of flight (MALDI-TOF) $\mathrm{ms}$ and tandem $\mathrm{ms}$, with fragments sequenced by the Michigan Proteome Consortium at the University of Michigan. Initial analysis involved searching the NCBInr database; subsequent analysis included BLAST searching the SwissProt database for proteins matching all peptide sequences from tandem mass spectrometry. Calculated $\mathrm{kDa}$ and $\mathrm{p} I$ values for proteins were obtained through SwissProt.

\section{Densitometric Analysis}

Regions of images from SDS-PAGE results were analyzed using ImageJ 1.33, with quantitation of grayscale values of pixels measured by ImageJ and plotted using GraphPad Prism 3.00.

\section{Results}

\section{Isolation of Fatty Acid-Associated Proteins}

Soluble proteins were used in this study, excluding membrane-associated proteins, which have extensive hydrophobic regions that would interact non-specifically with various FA (although many soluble proteins will also have accessible hydrophobic regions). As a first evaluation, proteins from these total soluble protein preparations were separated into those proteins that could be pulled down using different FA and those that were resistant to capture. Here, the polyunsaturated ARA (20 carbon, 4 double bonds) was compared with the saturated arachidic acid (ACH, 20:0). An initial evaluation of the proteins captured by fatty acids indicated that a surprisingly large number of proteins associated with both ARA and $\mathrm{ACH}$ (Fig. 1a). Prominent bands could be readily identified in the fatty acid-associated samples, which were largely absent from the fatty acid-depleted samples. Densitometric analysis of a region of the ARA-depleted sample (lane 2 ) and the ARA-associated samples (lane 3) indicated two major peaks that were unique to the latter sample (Fig. 1b). In addition, while many bands were associated with both ARA (lane 3) and ACH (lane 5), some bands appeared to be more abundant in one than the other (Fig. 1c), suggesting some degree of specificity. In control experiments, essentially no protein bound to beads alone or to beads after incubation with biotin alone without fatty acid, as determined by SDS-PAGE analysis of fractions eluted from washed beads processed in parallel (not shown).

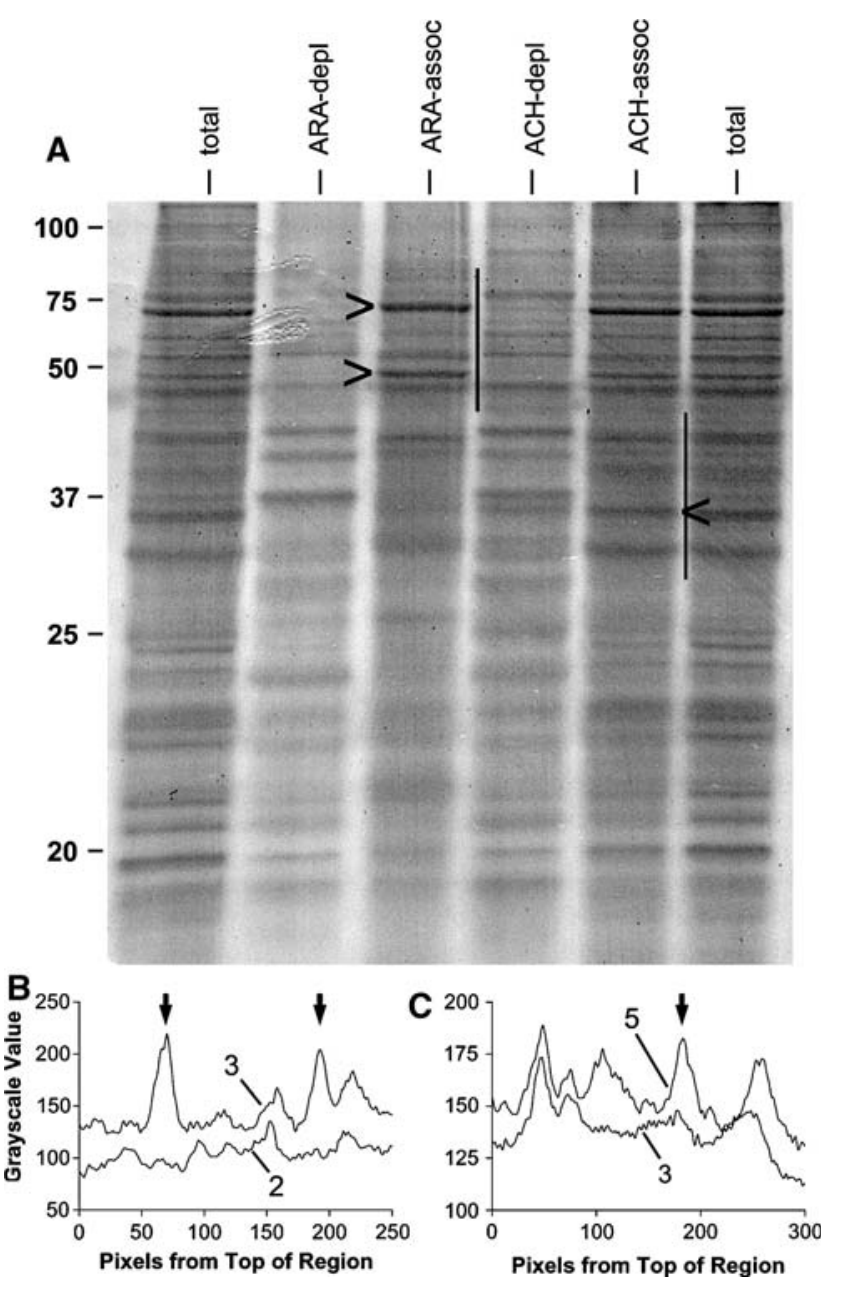

Fig. 1 Separation of ARA-associated proteins from proteins that do not associate with ARA from total soluble proteins of RBL1 cells. a SDS-PAGE analysis. Total soluble proteins of RBL1 cells ("total") were incubated with either ARA-biotin or ACH-biotin and the proteins that associated ("assoc") with the fatty acids were captured using avidin agarose. The remaining proteins, depleted of fatty acidassociated proteins, are also presented ("depl”). >, more abundant in ARA-assoc than ARA-depleted; <, more abundant in ACH-assoc than ARA-assoc. b Densitometric analysis of regions of ARA-depleted (2) and ARA-associated (3) lanes; region denoted by bar adjacent to lane 3. c Densitometric analysis of regions of ARA-associated (3) and $\mathrm{ACH}-a s s o c i a t e d(5)$ lanes; region corresponds to bar at lane 5

\section{Identification of Some ARA-Associating Proteins}

The large number of proteins that were pulled down by FA in this protocol indicated that additional separation steps would be required to identify individual FA-associating proteins. Parallel separation of total proteins and ARAassociated proteins by 2-dimensional gel electrophoresis again supported the conclusion that this protocol was capturing a subset of total proteins that bound ARA (Fig. 2).

Some of the most abundant (heavily staining) proteins that associated with ARA were identified by MALDI-TOF 


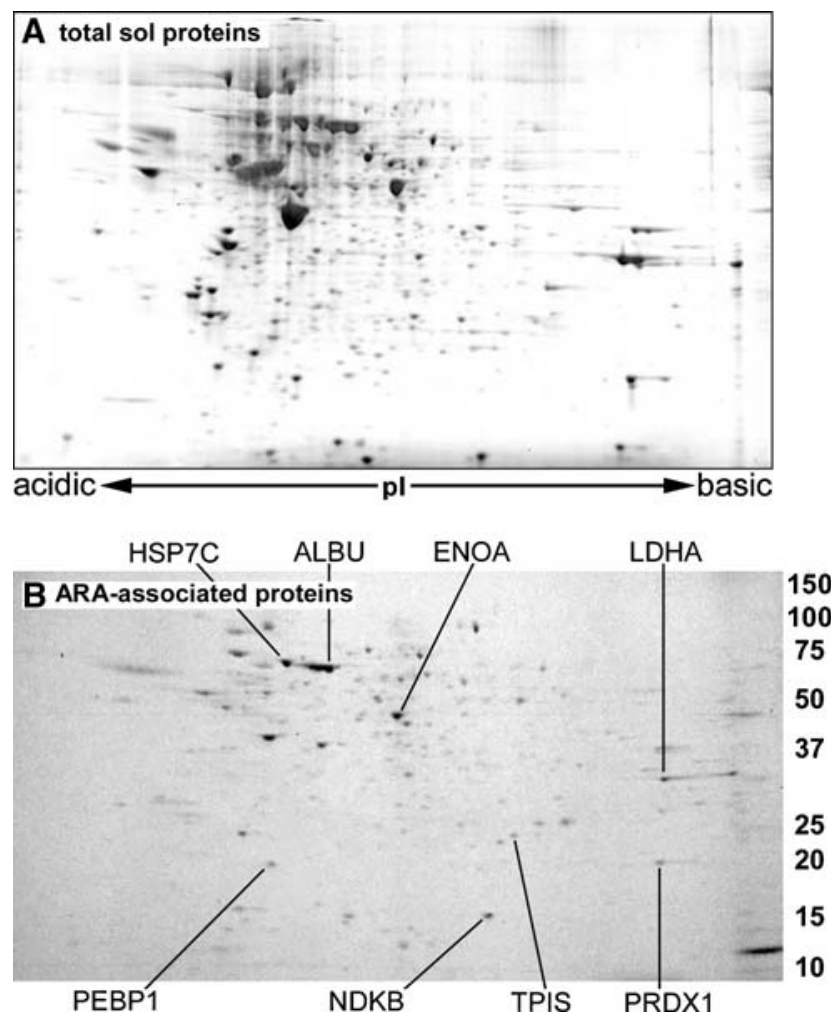

Fig. 2 Two-dimensional separation of total soluble proteins compared with ARA-associating proteins from RBL1 cells. a Total soluble proteins. b ARA-associating proteins. Coomassie-stained spots were analyzed by MALDI-TOF $\mathrm{ms} / \mathrm{ms}$ and sequenced peptides used to identify proteins. Abbreviations refer to proteins detailed in Table 1. Migration of molecular weight markers indicated at right of (b)

mass spectrometric analysis followed by database searches. In each case, individual peptide sequences were further queried by BLAST search for unique identities. For example, one protein provided the peptides FEELNADLFR, TTPSYVAFTDTER, IINEPTAAAIAYGLDK and TFTNAVVTVPAYFNDSQR; the first three peptides are shared by various heat shock proteins, including heat shock-related $70 \mathrm{kDa}$ protein 2 (HSP72), but the fourth peptide is unique to heat shock cognate $71 \mathrm{kDa}$ protein (HSP7C). The position of this protein on the two-dimensional gel, and some others that were positively identified, is indicated in Fig. 2b. Additional proteins that were identified as ARA-associating proteins are provided in Table 1, grouped according to function, with predicted $\mathrm{kDa}$ and $\mathrm{p} I$ values. Supporting their identification were correlations between the $\mathrm{kDa}$ and calculated $\mathrm{p} I$ values of the proteins and the position of the spots on the gels. Also, when peptide sequences were species specific, the identified isoform was from rat (or from mouse, if a rat protein sequence was not in SwissProt), consistent with these proteins being produced in a rat cell line.
Identification of Proteins Associating with 5-HETE and $\mathrm{LTB}_{4}$

As noted above, 5(S)-HETE can be a significant product of 5-LO metabolism of ARA. Several studies have examined the importance of the stereochemistry on function by comparing the effects of 5(S)-versus 5(R)-HETE. In short, some effects can be induced by both [24], whereas others are stereospecific $[25,26]$. We compared $5(S)$ - vs. $5(R)$ HETE in their capacity to bind proteins. Remarkably, both enantiomers retained many proteins (Fig. 3). Also, the similarity between the two sets of proteins was very high. Importantly, the major differences between the proteins were seen in horizontal groups of proteins (boxed in Fig. 3), which commonly represent proteins with different degrees of post-translational modification. Indeed, identification of selected pairs of spots using MALDI-TOF mass spectrometry verified that they were identical, recognized as Rho GDP-dissociation inhibitor 1 (GDIR), eukaryotic translation initiation factor 5A-2 (IF5A2), coactosin-like protein (COTL1) and SH3 domain-binding glutamic acidrich-like protein 3 (SH3L3). Typically, 5(S)-HETE selectively captured the more acidic version and 5(R)-HETE bound the more basic protein. Additional proteins identified from the 5(S)-HETE gel are listed in Table 2.

Finally, two-dimensional gel separation of proteins that associated with $\mathrm{LTB}_{4}$ revealed at least 20 proteins (not shown). A partial list of the most abundant proteins is given in Table 2. These are grouped according to known roles.

\section{Discussion}

This study presents a relatively simple and straightforward approach for capturing proteins that associate with PUFA and their derivatives. An asset of the approach is that it allows novel interactions to be discovered objectively. Through this approach, we have identified groups of proteins involved in protein synthesis, cytoskeletal function, Rho functioning and glycolysis that can associate with ARA. Some of these same proteins and roles are also shared with 5-HETE, suggesting that it can act like a second messenger akin to ARA. Perhaps most surprisingly, several proteins were found to associate with $\mathrm{LTB}_{4}$, a lipid mediator whose actions are thought to be solely receptormediated. This suggests that at least some of the effects of $\mathrm{LTB}_{4}$, as well as 5-HETE and ARA, may be through direct lipid-protein interactions.

Lipids, due to their hydrophobic nature, are first thought to associate with membranes. However, PUFA may have higher affinities for certain proteins than for membranes. For example, PUFA will partition into liposomal membranes in an aqueous solution, but will leave those 


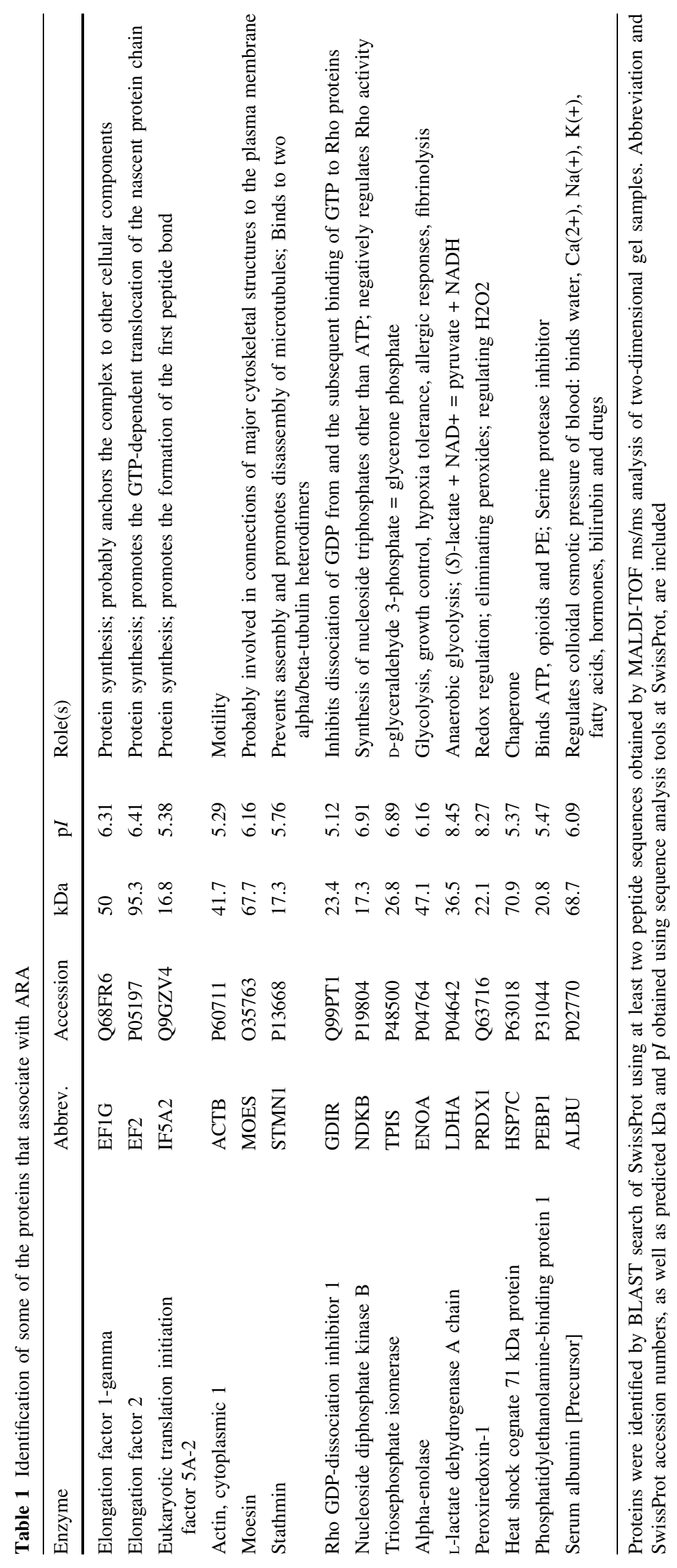




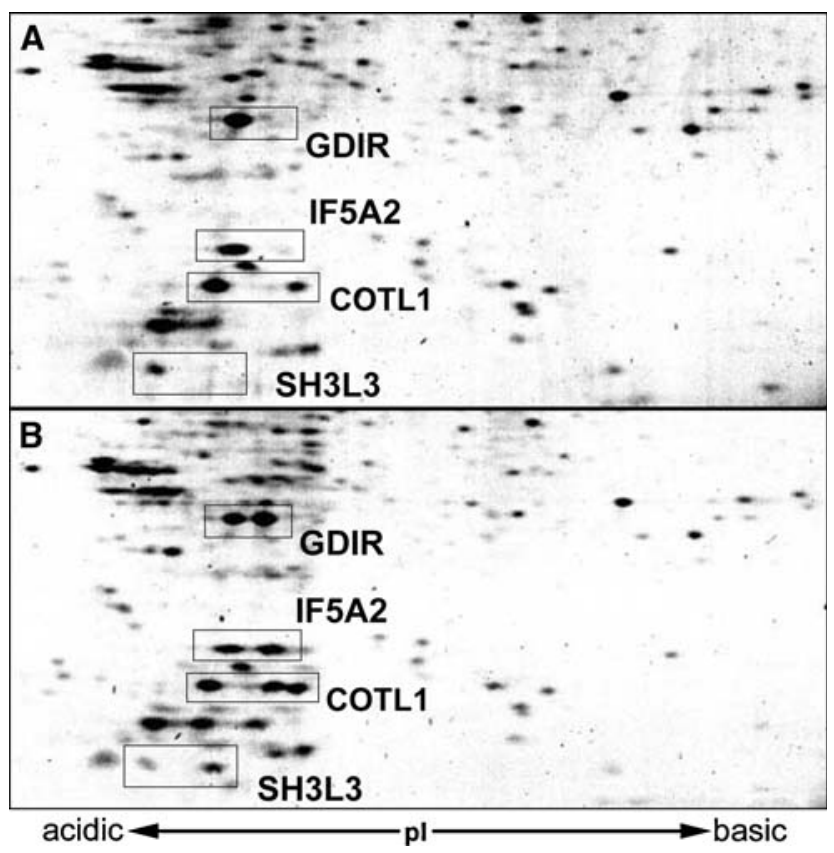

Fig. 3 Selected region of 2-D PAGE analysis of proteins that associate with $5(S)$-HETE versus $5(R)$-HETE. a 5(S)-HETE-associated proteins. b $5(R)$-HETE-associated proteins. Region corresponds to approx. $10-37 \mathrm{kDa}$ and $\mathrm{pI} 4.5-8$. Abbreviations refer to proteins detailed in Table 2

membranes to associate with added albumin [27]. Furthermore, ARA will leave albumin to associate with classical fatty acid-binding proteins (FABP), again due to differences in affinity. This indicates that soluble proteins, like albumin and FABP, can have higher affinities for PUFA than do liposomal membranes.

An important question may be whether previous studies support any of the PUFA-protein interactions here. That is, are any of these interactions biologically important, or do they just reflect the interaction of a lipid with a hydrophobic portion of a protein? First, the unique profile of proteins observed for each of the PUFA/eicosanoids argues against all of the interactions being non-specific interactions. Second, the capture of albumin, while not surprising, serves as a positive control. Albumin is recognized to serve the physiologically important function of regulating the colloidal osmotic pressure of blood through its binding of fatty acids, cations, hormones, bilirubin and drugs. Perhaps most intriguing is the case of the Rho GDP-dissociation inhibitor 1 (GDIR). It is well established that PUFA, including ARA, activate the production of reactive oxygen species in leukocytes [28, 29]. The GTP-bound (activated) form of Rac is required for activation of NADPH oxidase [30]. In resting leukocytes, GDIR inhibits the activation of Rac by directly binding to the GDP-bound (inactive) form of Rac, preventing guanine-nucleotide exchange and activation. In a comparison of the ability of different lipids to alter GDIR binding, ARA and other PUFA, but not saturated fatty acids, caused almost complete dissociation of GDIR from Rac, leading to activation of Rac [31]. The identification of the same protein binding to 5(S)-HETE suggests that this derivative of ARA may also modulate Rac activation through GDIR. Finally, similar approaches using biotinylation of 15 -deoxy- $\Delta^{12,14}$-prostaglandin $\mathrm{J}_{2}$ have been used to show that this $\mathrm{PGD}_{2}$ metabolite interacts with cytoskeletal $[32,33]$ and mitochondrial [34] proteins. These results underscore the versatility of this approach and strengthen the assertion that ARA metabolites may directly interact with proteins.

The role of PUFA to alter protein-protein interactions, demonstrated for GDIR [31], may also apply to other results from this study. Heat shock cognate $71 \mathrm{kDa}$ protein (HSP7C) was found to bind ARA. ARA has been shown to cause the dissociation of two HSP proteins, approx. 70 and $90 \mathrm{kDa}$, from protein phosphatase 5, leading to inactivation and degradation of the phosphatase [35], suggesting, at least that the interaction of ARA with HSP7C may serve to dissociate it from target proteins. In contrast with this, ARA has been shown to promote a physical interaction between phospholipase $\mathrm{C}-\gamma$ and a multimeric activating protein, AHNAK [36]. Similarly, ARA promotes translocation of p47-phox [37] and assembly of the NADPH oxidase complex [38]. Thus, PUFA may alter protein functions by facilitating the assembly or disassembly of protein complexes.

Many of the oxidized lipids that are produced from PUFA are relatively unstable and reactive. For example, the 5-LO product $\mathrm{LTA}_{4}$ has been shown to form stable adducts with nucleotides through covalent binding [39, 40]. Also, lipid hydroperoxides may be decomposed by antioxidants to produce DNA-reactive electrophiles [41]. Relevant to this study, biotinylated derivatives of 15-HETE have been shown to form complexes with proteins that are stable enough to withstand SDS-PAGE and electrophoretic transfer [42]. This suggests that some lipid-protein associations may be very stable.

Another interesting finding relates to L-lactate dehydrogenase A chain (LDHA), which is known to mediate the conversion of lactate to pyruvate, with concomitant generation of NADH from $\mathrm{NAD}^{+}$. Either transient hypoxia [43] or ischemia [44] produces a rapid release of arachidonic acid associated with a marked increase in lactate and decreases in pyruvate and ATP. It seems possible that arachidonic acid might directly associate with LDHA and inhibit lactate dehydrogenase activity.

Proteins also show specificity for specific PUFA. For example, the different FABP clearly favor certain PUFA over others [45]. Similarly, 5-lipoxygenase, which initiates the synthesis of LTs from ARA, prefers ARA over other PUFA [46] and was detected in ARA-associated proteins 


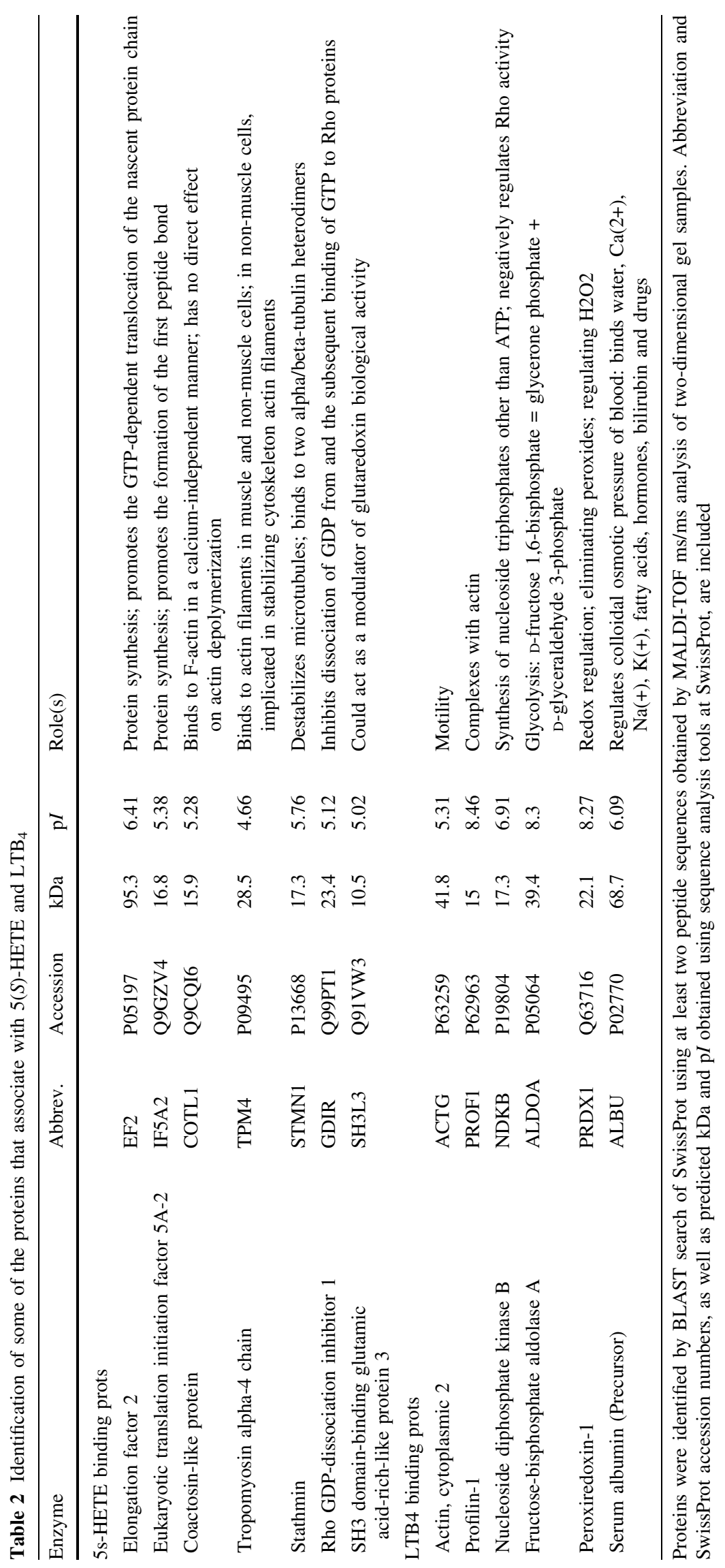


but not in the $\mathrm{ACH}$-associated proteins (not shown). Also, certain proteins were more abundant in the ACH-associated fraction than in the ARA-associated fractions (Fig. 1), suggesting specificity. This specificity must, at least in part, be due to the shape and structure of the PUFA. This specificity of protein for PUFA may be so exquisite that it may distinguish between stereochemistry of a hydroxyl group, as seen in the difference between the proteins that bind 5(S)- and 5(R)-HETE (Fig. 3).

The specificity of protein for PUFA points to a drawback of the approach used in this study. Since the biotin moiety is at the carboxyl terminus, proteins that specifically target that site will be missed. For example, FA associate with classical FABP, like the human epidermalFABP, with the carboxyl group of the FA directly interacting with side chains of key amino acids within the FABP [47]. As a result, this approach did not capture these well-known FABP, and perhaps many other proteins.

Another drawback of this approach is that it will not reveal which proteins interact directly with lipids, as opposed to those that associate indirectly by binding to a true PUFA-associating protein. For example, it is possible that the different cytoskeletal proteins (e.g., actin, moesin, stathmin, coactosin-like protein, profilin) may have been pulled down together, with only one of these proteins truly associating with ARA.

In summary, we present a relatively simple stepwise approach for the discovery of proteins that associate with PUFA and their derivatives. This approach can be used with any lipid with a free carboxyl terminus. Given the large number of proteins that were observed on the twodimensional gels presented here, it appears that PUFA interact with many proteins. The diversity of PUFA and PUFA derivatives suggests that numerous interactions can be discovered with this approach.

Acknowledgments This research was supported by generous funding from the Undergraduate Research Opportunities Program at the University of Michigan, as well as by National Institutes of Health grant R01 AI43574. The technical expertise of Lindsay Nixon and Rebecca Oas is also acknowledged.

\section{References}

1. Simopoulos AP, Leaf A, Salem NJ (1999) Workshop on the essentiality of and recommended dietary intakes for omega- 6 and omega-3 fatty acids. J Am Coll Nutr 18:487-489

2. de Deckere EAM, Korver O, Verschuren PM, Katan MB (1998) Health aspects of fish and n-3 polyunsaturated fatty acids from plant and marine origin. Eur J Clin Nutr 52:749-753

3. Hirafuji M, Machida T, Hamaue N, Minami M (2003) Cardiovascular protective effects of n-3 polyunsaturated fatty acids with special emphasis on docosahexaenoic acid. J Pharmacol Sci 92:308-316
4. Burr ML, Fehily AM, Rogers S, Welsby E, King S, Sandham S (1989) Diet and reinfarction trial (DART): design, recruitment, and compliance. Eur Heart J 10:558-567

5. Marchioli R, Barzi F, Bomba E, Chieffo C, Di Gregorio D, Di Mascio R, Franzosi MG, Geraci E, Levantesi G, Maggioni AP, Mantini L, Marfisi R, Mastrogiuseppe G, Mininni N, Nicolosi GL, Santini M, Schweiger C, Tavazzi L, Tognoni G, Tucci C, Valagussa F, Investigators G-P (2002) Early protection against sudden death by $n-3$ polyunsaturated fatty acids after myocardial infarction: time-course analysis of the results of the Gruppo Italiano per lo Studio della Sopravvivenza nell'Infarto Miocardico (GISSI)-Prevenzione. Circulation 105:1897-1903

6. Kang JX, Leaf A (1994) Effects of long-chain polyunsaturated fatty acids on the contraction of neonatal rat cardiac myocyte. Proc Natl Acad Sci USA 91:9886-9890

7. Xiao Y-F, Gomez AM, Morgan JP, Lederer WJ, Leaf A (1997) Suppression of voltage-gated L-type $\mathrm{Ca}^{2+}$ currents by polyunsaturated fatty acids in adult and neonatal rat ventricular myocytes. Proc Natl Acad Sci USA 94:4182-4187

8. Framework MGPR (1998) Thrombosis prevention trial: randomised trial of low-intensity oral anticoagulation with warfarin and low-dose aspirin in the primary prevention of ischemic heart disease in men at increased risk. Lancet 351:233-241

9. Ridker PM, Manson JE, Buring JE, Goldhaber SZ, Hennekens CH (1991) The effect of chronic platelet inhibition with low-dose aspirin on atherosclerotic progression and acute thrombosis: clinical evidence from the Physicians' Health Study. Am Heart J 122:1588-1592

10. Steering Committee PHSRG (1989) Final report on the aspirin component of the ongoing Physicians' Health Study. N Engl J Med 321:129-135

11. Murphy RC, Gijón MA (2007) Biosynthesis and metabolism of leukotrienes. Biochem J 405:379-395

12. Baskin DS, Ngo H, Didenko V (2003) Thimerosal induces DNA breaks, caspase- 3 activation, membrane damage, and cell death in cultured human neurons and fibroblasts. Toxicol Sci 74:361-368

13. Woo KJ, Lee TJ, Bae JH, Jang BC, Song DK, Cho JW, Suh SI, Park JW, Kwon TK (2006) Thimerosal induces apoptosis and G2/ M phase arrest in human leukemia cells. Mol Carcinog 45:657666

14. Cao Y, Pearman AT, Zimmerman GA, McIntyre TM, Prescott SM (2000) Intracellular unesterified arachidonic acid signals apoptosis. Proc Natl Acad Sci USA 97:11280-11285

15. Tinel H, Wehner F, Kinne RK (1997) Arachidonic acid as a second messenger for hypotonicity-induced calcium transients in rat IMCD cells. Pflugers Arch 433:245-253

16. van der Zee L, Nelemans A, den Hertog A (1995) Arachidonic acid is functioning as a second messenger in activating the $\mathrm{Ca}^{2+}$ entry process on H1-histaminoceptor stimulation in DDT1 MF-2 cells. Biochem J 305:859-864

17. Flamand N, Mancuso P, Serezani CHC, Brock TG (2007) Leukotrienes: mediators that have been typecast as villains. Cell Mol Life Sci 64:2657-2670

18. Yokomizo T, Izumi T, Chang K, Takuwa Y, Shimizu T (1997) A G-protein-coupled receptor for leukotriene $\mathrm{B}_{4}$ that mediates chemotaxis. Nature 387:620-624

19. Yokomizo T, Kato K, Terawaki K, Izumi T, Shimizu T (2000) A second leukotriene $\mathrm{B}(4)$ receptor, BLT2. A new therapeutic target in inflammation and immunological disorders. J Exp Med 192:421-432

20. Skinner J, Sinclair C, Romeo C, Armstrong D, Charbonneau H, Rossie S (1997) Purification of a fatty acid-stimulated proteinserine/threonine phosphatase from bovine brain and its identification as a homolog of protein phosphatase 5. J Biol Chem 272:22464-22471 
21. Siegenthaler G, Roulin K, Chatellard-Gruaz D, Holtz R, Saurat JH, Hellman U, Hagens G (1997) A heterocomplex formed by the calcium-binding proteins MRP8 (S100-A8) and MRP-14 (S100A9) binds unsaturated fatty acids with high affinity. J Biol Chem 272:9371-9377

22. Bouzidi F, Doussiere J (2004) Binding of arachidonic acid to myeloid-related proteins (S100A8/A9) enhances phagocytic NADPH oxidase activation. Biochem Biophys Res Commun 325:1060-1065

23. Abramson SB, Leszczynska-Piziak J, Weissmann G (1991) Arachidonic acid as a second messenger. Interactions with a GTPbinding protein of human neutrophils. J Immunol 147:231-236

24. Bittleman DB, Casale TB (1995) 5-Hydroxyeicosatetraenoic acid (HETE)-induced neutrophil transcellular migration is dependent upon enantiomeric structure. Am J Respir Cell Mol Biol 12:260267

25. Rossi AG, Thomas MJ, O'Flaherty JT (1988) Stereospecific bioactions of 5-hydroxyeicosatetraenoate. FEBS Lett 240:163-166

26. O'Flaherty J, Rossi A (1993) 5-Hydroxyicosatetraenoate stimulates neutrophils by a stereospecific, $\mathrm{G}$ protein-linked mechanism. J Biol Chem 268:14708-14714

27. Ek-Von Mentzer BA, Zhang F, Hamilton JA (2001) Binding of 13-HODE and 15-HETE to phospholipid bilayers, albumin, and intracellular fatty acid binding proteins. Implications for transmembrane and intracellular transport and for protection from lipid peroxidation. J Biol Chem 276:15575-15580

28. Kakinuma K (1974) Effects of fatty acids on the oxidative metabolism of leukocytes. Biochim Biophys Acta 348:76-85

29. Badwey J, Curnutte J, Karnovsky M (1981) cis-polyunsaturated fatty acids induce high levels of superoxide production by human neutrophils. J Biol Chem 256:12640-12643

30. Heyworth PG, Knaus UG, Xu X, Uhlinger DJ, Conroy L, Bokoch GM, Curnutte JT (1993) Requirement for posttranslational processing of Rac GTP-binding proteins for activation of human neutrophil NADPH oxidase. Mol Biol Cell 4:261-269

31. Chuang TH, Bohl BP, Bokoch GM (1993) Biologically active lipids are regulators of Rac.GDI complexation. J Biol Chem 268:26206-26211

32. Stamatakis K, Sánchez-Gómez FJ, Pérez-Sala D (2006) Identification of novel protein targets for modification by 15-deoxyDelta12,14-prostaglandin $\mathrm{J}_{2}$ in mesangial cells reveals multiple interactions with the cytoskeleton. J Am Soc Nephrol 17:89-98

33. Aldini G, Carini M, Vistoli G, Shibata T, Kusano Y, Gamberoni L, Dalle-Donne I, Milzani A, Uchida K (2007) Identification of actin as a 15-deoxy-Delta12,14-prostaglandin $\mathrm{J}_{2}$ target in neuroblastoma cells: mass spectrometric, computational, and functional approaches to investigate the effect on cytoskeletal derangement. Biochemistry 46:2707-2718

34. Landar A, Shiva S, Levonen AL, Oh J-Y, Zaragoza C, Johnson MS, Darley-Usmar VM (2006) Induction of the permeability transition and cytochrome c release by 15-deoxy-Delta12,14prostaglandin $\mathrm{J}_{2}$ in mitochondria. Biochem J 394:185-195

35. Zeke T, Morrice N, Vázquez-Martin C, Cohen PT (2005) Human protein phosphatase 5 dissociates from heat-shock proteins and is proteolytically activated in response to arachidonic acid and the microtubule-depolymerizing drug nocodazole. Biochem J 385:45-56

36. Sekiya F, Bae YS, Jhon DY, Hwang SC, Rhee SG (1999) AHNAK, a protein that binds and activates phospholipase $\mathrm{C}-\gamma 1$ in the presence of arachidonic acid. J Biol Chem 274:13900-13907

37. Sellmayer A, Obermeier H, Danesch U, Aepfelbacher M, Weber PC (1996) Arachidonic acid increases activation of NADPH oxidase in monocytic U937 cells by accelerated translocation of p47-phox and co-stimulation of protein kinase C. Cell Signal 8:397-402

38. Uhlinger DJ, Tyagi SR, Inge KL, Lambeth JD (1993) The respiratory burst oxidase of human neutrophils. Guanine nucleotides and arachidonate regulate the assembly of a multicomponent complex in a semirecombinant cell-free system. J Biol Chem 268:8624-8631

39. Reiber DC, Murphy RC (2000) Covalent binding of $\mathrm{LTA}_{4}$ to nucleosides and nucleotides. Arch Biochem Biophys 379:119-26

40. Hankin JA, Jones DN, Murphy RC (2003) Covalent binding of leukotriene $\mathrm{A}_{4}$ to DNA and RNA. Chem Res Toxicol 16:551-561

41. Lee SH, Oe T, Blair IA (2001) Vitamin C-induced decomposition of lipid hydroperoxides to endogenous genotoxins. Science 292:2083-2086

42. Kang LT, Vanderhoek JY (1997) Synthesis and use of a novel biotinylated probe for the chemiluminescent detection of proteins that bind 15-hydroxyeicosatetraenoic acid. Anal Biochem 250:119-122

43. Ikeda M, Busto R, Yoshida S, Santiso M, Martinez E, Ginsberg MD (1988) Cerebral phosphoinositide, triacylglycerol and energy metabolism during severe hypoxia and recovery. Brain Res 459:344-350

44. Katayama Y, Shimizu J, Suzuki S, Perrier H, Prasit P, Wang Z, Vickers PJ (1990) Role of arachidonic acid metabolism on ischemic brain edema and metabolism. Adv Neurol 52:105-108

45. Zimmerman AW, van Moerkerk HT, Veerkamp JH (2001) Ligand specificity and conformational stability of human fatty acid-binding proteins. Int J Biochem Cell Biol 33:865-876

46. Charleson S, Evans JF, Léger S, Perrier H, Prasit P, Wang Z, Vickers PJ (1994) Structural requirements for the binding of fatty acids to 5-lipoxygenase-activating protein. Eur J Pharmacol 267:275-280

47. Hohoff C, Börchers T, Rüstow B, Spener F, van Tilbeurgh H (1999) Expression, purification, and crystal structure determination of recombinant human epidermal-type fatty acid binding protein. Biochemistry 38:12229-12239 